\title{
Comparison of ultrasonography and histopathology for the diagnosis of endometritis in Holstein-Friesian cows
}

\author{
E. B. S. Meira Jr., ${ }^{\star 1}$ L. C. S. Henriques, ${ }^{\star}$ L. R. M. Sá, $†$ and L. Gregory ${ }^{\star}$ \\ *Department of Clinical Sciences, and \\ †Department of Pathology, Universidade de São Paulo, São Paulo, 05508 270, Brazil
}

\begin{abstract}
Reproductive diseases are a great barrier to dairy production, as they diminish fertility and cause economic loss. In this context, endometritis plays an important role. Different diagnostic techniques exist for endometritis that vary in sensitivity and specificity. This work aimed to evaluate and compare ultrasonographic and histopathological examinations, and combinations thereof, for the diagnosis of endometritis by determining their sensitivity, specificity, and kappa agreement coefficients using endometrial cytology as the gold standard. We developed an adaptive reading score to perform histological examination of the uterus. In this study, 76 Holstein-Friesian cows, 21 to $47 \mathrm{~d}$ postpartum, without vaginal catarrh were submitted to gynecological examinations, including ultrasonographic examination, an endometrial cytology examination, and a uterine biopsy. Our results indicate that ultrasonography is a practical and effective diagnostic method, and a combination of the determination of intrauterine fluid and cervical diameter was the most efficient ultrasonographic method, with $50 \%$ sensitivity and $88 \%$ specificity. Histopathological examination was a useful diagnostic method that provided rich detail on endometrial inflammation, and allowed evaluation of different components of the tissue such as the epithelium, lamina propria, endometrial glands, and blood vessels; this method had $44 \%$ sensitivity and $92 \%$ specificity for diagnosis of endometritis.
\end{abstract}

Key words: endometritis, ultrasonography, histopathology

\section{INTRODUCTION}

Poor reproductive performance is a productionlimiting factor (Gröhn and Rajala-Schultz, 2000); this condition affects herd profitability by reducing yields of

Received September 19, 2011.

Accepted May 8, 2012.

${ }^{1}$ Corresponding author: ejmeira@hotmail.com milk and the number of calves produced and by increasing the number of days open and the rate of culling (Fourichon et al., 2000; Gröhn and Rajala-Schultz, 2000; Drillich et al., 2005; LeBlanc, 2007).

Endometritis is a superficial inflammation limited to the endometrium and extending no deeper than the stratum spongiosum. Histologically, endometritis is characterized by disruption of the surface epithelium, infiltration with inflammatory cells, vascular congestion, and stromal edema, with varying degrees of lymphocyte and plasma cell accumulation in the superficial layers (Kennedy and Miller, 1993; Bondurant, 1999). Sheldon et al. (2009) proposed that clinical endometritis should be defined by the presence of purulent genital discharge after $21 \mathrm{~d}$ postpartum, by presence of mucopurulent discharge after $26 \mathrm{~d}$ postpartum in the absence of systemic signs, or both. It was recently proposed that the term "purulent vaginal discharge" be used instead of clinical endometritis, because the presence of genital catarrh was not necessarily indicative of endometrial inflammation (Dubuc et al., 2010). Subclinical endometritis is defined as inflammation of the endometrium, usually determined by endometrial cytology, with the absence of purulent vaginal discharge indentified by vaginoscopy. In animals without clinical signs, the disease is diagnosed by measuring the polymorphonuclear cell proportion on a slide made from cells collected by cytobrush or uterine lavage techniques (Sheldon et al., 2009).

Despite the significant economic impact of uterine infection, some controversy still exists around its diagnosis (Kinsel, 1996). The efficiency of different diagnostic techniques has been studied by many researchers (Miller et al., 1980; Bonnett et al., 1991a,b,c; LeBlanc et al., 2002; Kasimanickam et al., 2004; Williams et al., 2005; Barlund et al., 2008; Oral et al., 2009).

Mateus et al. (2002) noted that ultrasound uterine measurement was easy and allowed reliable comparison of results. Ultrasonographic intrauterine fluid determination after wk 3 postpartum is a reliable diagnostic method for endometritis, with good sensitivity and specificity (Mateus et al., 2002; Kasimanickam et al., 2004; Barlund et al., 2008; Oral et al., 2009). Uterine 
biopsy allows for endometrial morphologic analysis, a technique with results that may correlate with bovine infertility, assuming the sample is representative of both uterine horns (Bonnett et al., 1991c; Rodriguez et al., 1991). Uterine biopsy has been reported to be a safe and reliable technique for assessing uterine function and health (DeBois and Manspeaker, 1986; Chapwanya et al., 2010).

The present study aimed to evaluate and compare ultrasound and uterine biopsy in their capacity to establish the correct diagnosis of endometritis as defined by uterine cytology.

\section{MATERIALS AND METHODS}

The present study involved the gynecological examination of 76 Holstein-Friesian cows between 21 and 47 d postpartum that presented no genital catarrh on vaginoscopy and were submitted to ultrasound examinations and cellular harvesting by cytobrush, and biopsy.

On the transrectal ultrasonographic examination of the reproductive tract (Falcon, Pie Medical Imaging BV, Maastricht, the Netherlands), cervical and previously gravid uterine horn base diameters were measured, and the presence of fluid in the uterus was evaluated; if any amount of intraluminal fluid was recognized, it would be classified as positive for endometrial inflammation. Cervical and previously gravid uterine horn base size were classified as small, medium, and large $(<3.5$, 3.5 to 5.0 , and $>5 \mathrm{~cm}$, respectively), according to the study by Kasimanickam et al. (2004). When measuring cervix and uterine horn size, a 5-cm cut-off point was used to diagnose endometritis according to the concept established by Gier and Marion (1968). Each measurement variable and their combinations were evaluated as separate ultrasonographic examinations.

Endometrial cytology samples were collected using the cytobrush technique, and cytological examination was performed according to the method and cut-off points for endometritis diagnosis described by Kasimanickam et al. (2004): if $>18 \%$ polymorphonuclear cells were identified 21 to $33 \mathrm{~d}$ postpartum or $\geq 10 \%$ polymorphonuclear cells were identified 34 to $47 \mathrm{~d}$ postpartum, the animal was considered positive for subclinical endometritis.

Uterine biopsy fragments were collected from the previously gravid uterine horn by transcervical access using a 65-cm-long stainless steel Yeoman biopsy forceps (Hauptner, Solingen, Germany). The fragment was approximately $5 \mathrm{~mm}$ long, $2 \mathrm{~mm}$ high, and $2 \mathrm{~mm}$ deep. The evaluation criteria were adapted from the studies by Gonzalez et al. (1985) and Bonnett et al. (1991a,b,c), and a summation score was developed. This score was composed by summing 4 scores that reflected the surface epithelium, the lamina propria, the endometrial glands, and the vascular inflammatory status, respectively (Table 1 ).

For the histopathological diagnosis of endometritis, the cut-off point of 15 was defined using SPSS 16.0 for Windows (SPSS Inc., Chicago, IL) to obtain the best sensitivity and specificity by calculating receiver operating characteristics curves using endometrial cytology as the gold standard.

Sensitivity, specificity, and the concordance coefficient kappa were determined for ultrasonographic examinations, biopsy, and the combination of these, according the criteria established by Smith (1991); endometrial cytology was the gold standard. The confidence interval was calculated by using Minitab software, version 15.1.0.1. (2006, Minitab Inc., State College, PA).

\section{RESULTS}

Sixteen of 76 animals examined by cytobrush technique were positive for subclinical endometritis. The results of the evaluations of the diagnostic techniques are summarized in Table 2.

Assessing fluid accumulation in the uterus was most effective when using isolated ultrasound examination and had sensitivity, specificity, and concordance coefficient (kappa) values of 88,62 , and $33 \%$, respectively. The combination of intraluminal fluid assessment and cervical measurement, with a cut-off point of $>5.0 \mathrm{~cm}$, was the best of all ultrasonographic examinations, with $50 \%$ sensitivity, $88 \%$ specificity, and 39\% kappa. Combining 3 ultrasonographic evaluations, the association between intrauterine fluid accumulation, cervical, and previously gravid horn base measurement, with a cutoff point of $>5.0 \mathrm{~cm}$, had sensitivity, specificity, and kappa values of 31,93 , and $29 \%$, respectively.

Uterine biopsy produced, in this study, $59.2 \%(45 / 76)$ readable samples. On this group of readable samples, 9 of 45 were taken from animals diagnosed with endometritis by cytological examination. The summation score used as biopsy reading criterion had sensitivity, specificity, and kappa values of 44, 92, and 39\%, respectively. The partial scores and their associations were shown to be effective. The best combination was the score that represented the epithelium, lamina propria, and vascular inflammation status; this association had sensitivity, specificity, and kappa values of 78,81 , and $48 \%$, respectively.

The association of ultrasonographic examinations and uterine biopsy showed that combining intraluminal fluid assessment and biopsy had sensitivity, specificity, and kappa values of 44,94 , and $44 \%$, respectively; the combination of cervical measurement and biopsy had sensitivity, specificity, and kappa values of 44, 97, and 
Table 1. Histopathological exam criteria for endometritis diagnosis

\begin{tabular}{|c|c|c|}
\hline Variable & Category & Score (range) \\
\hline \multicolumn{2}{|l|}{ Epithelium } & Score $(1-11)$ \\
\hline \multirow[t]{3}{*}{ Height } & Columnar & 1 \\
\hline & Cuboidal & 2 \\
\hline & Flattened & 3 \\
\hline \multirow[t]{4}{*}{ Epithelial damage } & Absent & 0 \\
\hline & Mild & 1 \\
\hline & Moderate & 2 \\
\hline & Ulcer & 3 \\
\hline \multirow[t]{3}{*}{ Inflammatory cell type } & Absent & 0 \\
\hline & Mononuclear & 1 \\
\hline & Polymorphonuclear & 2 \\
\hline \multirow[t]{4}{*}{ Infiltrate intensity } & Absent & 0 \\
\hline & Mild $\left(\leq 5\right.$ cells $\left./ \mathrm{hpf} ; \times 40^{1}\right)$ & 1 \\
\hline & Moderate $(\geq 6-10$ cells/hpf; $\times 40)$ & 2 \\
\hline & Severe $(>10$ cells $/ \mathrm{hpf} ; \times 40)$ & 3 \\
\hline \multicolumn{2}{|l|}{ Lamina propria } & Score $(0-8)$ \\
\hline \multirow[t]{3}{*}{ Inflammatory cell type } & Absent & 0 \\
\hline & Mononuclear & 1 \\
\hline & Polymorphonuclear & 2 \\
\hline \multirow[t]{4}{*}{ Infiltrate intensity } & Normal $(\leq 20$ cells/hpf; $\times 40)$ & 0 \\
\hline & Mild $(\geq 21-40$ cells/hpf; $\times 40)$ & 1 \\
\hline & Moderate $(\geq 41-70$ cells $/ \mathrm{hpf} ; \times 40)$ & 2 \\
\hline & Severe $(>70$ cells $/ \mathrm{hpf} ; \times 40)$ & 3 \\
\hline \multirow[t]{4}{*}{ Lymphocytic aggregates } & Absent & 0 \\
\hline & Mild $(\leq 3$ aggregates $/ \mathrm{hpf} ; \times 10)$ & 1 \\
\hline & Moderate $(\geq 4-5$ aggregates $/ \mathrm{hpf} ; \times 10)$ & 2 \\
\hline & Severe $(\geq 6$ aggregates $/ \mathrm{hpf} ; \times 10)$ & 3 \\
\hline \multicolumn{2}{|l|}{ Endometrial gland } & Score $(0-4)$ \\
\hline \multirow[t]{2}{*}{ Atrophy or dilation } & Absent & 0 \\
\hline & Present & 1 \\
\hline \multirow[t]{4}{*}{ Fibrosis } & Absent & 0 \\
\hline & Mild (1-3 layers/hpf; ×40) & 1 \\
\hline & Moderate $(4-5$ layers $/ \mathrm{hpf} ; \times 40)$ & 2 \\
\hline & Severe $(\geq 6$ layers $/ \mathrm{hpf} ; \times 40)$ & 3 \\
\hline \multicolumn{2}{|l|}{ Vascular } & Score $(0-3)$ \\
\hline \multirow[t]{2}{*}{ Vessel degeneration } & Absent & 0 \\
\hline & Present & 1 \\
\hline \multirow[t]{2}{*}{ Hemorrhage } & Absent & 0 \\
\hline & Present & 1 \\
\hline \multirow[t]{2}{*}{ Hemosiderin macrophages } & Absent & 0 \\
\hline & Present & 1 \\
\hline \multicolumn{2}{|l|}{ Total } & Score (1-26) \\
\hline
\end{tabular}

${ }^{1}$ Per high power field at the stated magnification $(\times 10$ or $\times 40)$.

$50 \%$, respectively; and the combination of all 3 exams (biopsy, intraluminal fluid accumulation assessment, and cervical size determination) had sensitivity, specificity, and kappa values of 44,97, and 50\%, respectively.

\section{DISCUSSION}

This study focused on evaluating diagnostic methods for endometritis. We analyzed the sensitivity and specificity of each of these methods and their associations. Sheldon et al. (2006) explained the difficulty in estimating sensitivity and specificity of the diagnostic methods of endometritis, given that it is hard to find a gold standard. One alternative method is reproductive performance, evaluated by diagnosing pregnancy at 120 d; however, this method will never achieve $100 \%$ sensitivity because many factors lead to infertility (LeBlanc et al., 2002).

Subclinical endometritis is defined as superficial inflammation of the endometrium and is diagnosed by endometrial cytology with the absence of purulent vaginal discharge. Animals without clinical signs can be diagnosed with this disease based upon the proportion of neutrophils in the cytological examination (Sheldon et al., 2006). In this study, the gold standard was endometrial cytology. 
Table 2. Comparison of diagnostic techniques to cytology

\begin{tabular}{lccrl}
\hline Diagnostic technique $^{1}$ & $\begin{array}{c}\text { Positive, } \\
\text { no./total }\end{array}$ & $\begin{array}{c}\text { Sensitivity, } \\
(95 \% \text { CI })\end{array}$ & $\begin{array}{c}\text { Specificity, } \% \\
(95 \% \text { CI })\end{array}$ & $\kappa^{2}(P$-value $)$ \\
\hline FIU & $37 / 76$ & $88(0.62 ; 0.99)$ & $62(0.48 ; 0.74)$ & $0.33(0.0004)$ \\
CM & $25 / 76$ & $56(0.30 ; 0.80)$ & $73(0.60 ; 0.83)$ & $0.25(0.0252)$ \\
PHB & $24 / 76$ & $38(0.15 ; 0.64)$ & $70(0.56 ; 0.81)$ & $0.06(0.5663)$ \\
FIU + CM & $15 / 76$ & $50(0.25 ; 0.75)$ & $88(0.77 ; 0.95)$ & $0.39(0.001)$ \\
FIU + PHB & $15 / 76$ & $38(0.15 ; 0.64)$ & $85(0.73 ; 0.93)$ & $0.23(0.045)$ \\
CM + PHB & $12 / 76$ & $31(0.11 ; 0.59)$ & $88(0.77 ; 0.95)$ & $0.22(0.056)$ \\
FIU + CM + PHB & $09 / 76$ & $31(0.11 ; 0.59)$ & $93(0.84 ; 0.98)$ & $0.29(0.006)$ \\
Biopsy & $07 / 45$ & $44(0.14 ; 0.79)$ & $92(0.78 ; 0.98)$ & $0.39(0.0075)$ \\
FIU + biopsy & $06 / 45$ & $44(0.14 ; 0.79)$ & $94(0.81 ; 0.99)$ & $0.44(0.002)$ \\
CM + biopsy & $05 / 45$ & $44(0.14 ; 0.79)$ & $97(0.85 ; 0.99)$ & $0.50(0.0003)$ \\
PHB + biopsy & $02 / 45$ & $22(0.03 ; 0.60)$ & $100(0.92 ; 1.00)$ & $0.31(0.004)$ \\
FIU + CM + biopsy & $05 / 45$ & $44(0.14 ; 0.79)$ & $97(0.85 ; 0.99)$ & $0.50(0.0003)$ \\
FIU + PHB + biopsy & $02 / 45$ & $22(0.03 ; 0.60)$ & $100(0.92 ; 1.00)$ & $0.31(0.004)$ \\
CM + PHB + biopsy & $02 / 45$ & $22(0.03 ; 0.60)$ & $100(0.92 ; 1.00)$ & $0.31(0.004)$ \\
FIU + CM + PHB + biopsy & $02 / 45$ & $22(0.03 ; 0.60)$ & $100(0.92 ; 1.00)$ & $0.31(0.004)$ \\
\hline
\end{tabular}

${ }^{1} \mathrm{FIU}=$ fluid in uterus ultrasonographic assessment; $\mathrm{CM}=$ ultrasonographic cervical measuring cut-off $>5.0$ $\mathrm{cm} ; \mathrm{PHB}=$ ultrasonographic previously gravid uterine horn base measuring cut-off $>5.0 \mathrm{~cm}$.

${ }^{2}$ Kappa value $=$ concordance coefficient.

Okano and Tomizuka (1987) and Sheldon et al. (2006) reported that ultrasound examination is an objective, noninvasive, practical, and exact method. This work agrees with such a statement when the diagnosis can be made in real time taking exact measures. After birth, the uterus is enlarged; uterine macroscopic involution occurs 3 to 5 wk postpartum, when a healthy uterine horn must have a diameter smaller than $5 \mathrm{~cm}$ (Gier and Marion, 1968). Slama et al. (1991) proved that uterine infections predispose to a delayed uterine involution. LeBlanc et al. (2002) showed that animals with a delayed cervical involution often demonstrate poorer reproductive performance compared with animals diagnosed as normal. This study found that cervical measurement is an interesting tool for the diagnosis of endometritis, but its efficiency can be increased when combined with other observations such as the presence of intraluminal fluid. Although it is a subjective assessment, determination of fluid in the uterus was a reliable technique in this study, having good specificity, as documented in other studies (Mateus et al., 2002; Kasimanickam et al., 2004; Barlund et al., 2008; Oral et al., 2009). The present study found that the association of the finding of fluid in the uterus and cervical measuring constitutes is the best ultrasonographic examination to assess uterine postpartum health.

An objective summation score was developed in this study for the histopathological diagnosis of endometritis. The evaluation found that biopsy was a useful and very specific diagnostic method for endometritis, the histopathological examination providing a rich understanding of the degree of inflammation of the tissue and details of the lesions that may exist.
Overall, Bonnett et al. (1991a,b,c) produced 70\% readable biopsies; in this study, approximately $60 \%$ of the biopsies were performed at this level of quality. Bonnett et al. (1993) had found sensitivity of $92 \%$ and specificity of $77 \%$ for biopsy, using pregnancy at $120 \mathrm{~d}$ postpartum as a reference. The present work found a sensitivity of $44 \%$ and specificity of $92 \%$ for the diagnosis of subclinical endometritis using cytology as a gold standard.

Uterine biopsy is an invasive technique, and the possibility exists of impairment in reproductive performance caused by biopsy. DeBois and Manspeaker (1986) and Chapwanya et al. (2010) showed that uterine biopsy is a safe technique, whereas Bonnett et al. (1993) showed that it might impair reproductive performance. The latter study used a punch that collected a larger fragment than the one collected using the Yeoman biopsy forceps used by DeBois and Manspeaker (1986) and Chapwanya et al. (2010). Even though uterine biopsy may cause an increase in days open, this work proved that it is a very specific diagnostic method.

The summation score was shown to be effective, but the evaluation of partial scores and their associations revealed that the combination that excluded the glandular inflammation status had the best diagnostic efficiency, with $78 \%$ sensitivity and $94 \%$ specificity, probably because the animals selected in this study had no uterine discharge, suggesting a minor involvement of endometrial glands in the inflammation process during subclinical endometritis. This finding suggests that more research must be conducted to define which glandular inflammatory lesions have real importance for subclinical endometritis. The combination of ul- 
trasonographic examination and biopsy improved specificity.

\section{CONCLUSIONS}

Comparing and evaluating diagnostic methods for endometritis confirmed that ultrasonography is an efficient method, providing an easy and fast diagnosis. The combination of fluid assessment and cervical measurement with a cut-off point of $>5 \mathrm{~cm}$ was the best ultrasonographic examination technique. Uterine biopsy is a highly specific diagnostic method that provides valuable detail about tissue inflammation and the respective lesions.

\section{ACKNOWLEDGMENTS}

The authors thank Fundação de Amparo a Pesquisa do Estado de São Paulo (FAPESP, São Paulo, Brazil) for funding this study.

\section{REFERENCES}

Barlund, C. S., T. D. Carruthers, C. L. Waldner, and C. W. Palmer. 2008. A comparison of diagnostic techniques for postpartum endometritis in dairy cattle. Theriogenology 69:714-723.

Bondurant, R. H. 1999. Inflammation in the bovine female reproductive tract. J. Anim. Sci. 77(Suppl. 2):101-110.

Bonnett, B. N., S. W. Martin, V. P. Gannon, R. B. Miller, and W. G. Etherington. 1991a. Endometrial biopsy in Holstein-Friesian dairy cows. III. Bacteriological analysis and correlations with histological findings. Can. J. Vet. Res. 55:168-173.

Bonnett, B. N., S. W. Martin, and A. H. Meek. 1993. Associations of clinical findings, bacteriological and histological results of endometrial biopsy with reproductive performance of postpartum dairy cows. Prev. Vet. Med. 15:205-210.

Bonnett, B. N., R. B. Miller, W. G. Etherington, S. W. Martin, and W. H. Johnson. 1991b. Endometrial biopsy in Holstein-Friesian dairy cows. I. Technique, histological criteria and results. Can. J. Vet. Res. 55:155-161.

Bonnett, B. N., R. B. Miller, S. W. Martin, W. G. Etherington, and B. C. Buckrell. 1991c. Endometrial biopsy in Holstein-Friesian dairy cows. II. Correlations between histological criteria. Can. J. Vet. Res. 55:162-167.

Chapwanya, A., K. G. Meade, F. Narciandi, P. Stanley, J. F. Mee, M. L. Doherty, J. J. Callanan, and C. O'Farrely. 2010. Endometrial biopsy: A valuable clinical and research tool on bovine reproduction. Theriogenology 73:988-994.

DeBois, C. H. W., and J. E. Manspeaker. 1986. Endometrial biopsy of the bovine. Pages 424-426 in Current Therapy in Theriogenology: Diagnosis, Treatment and Prevention of Reproductive Diseases in Animals. 2nd ed. D. A. Morrow, ed. W. B. Saunders, Philadelphia, PA.

Drillich, M., W. Raab, M. Wittike, and W. Heuwiesier. 2005. Treatment of chronic endometritis with an intrauterine application of enzymes: A field trial. Theriogenology 63:1811-1823.

Dubuc, J., T. F. Duffield, K. E. Leslie, J. S. Walton, and S. J. LeBlanc. 2010. Definitions and diagnosis of postpartum endometritis in dairy cows. J. Dairy Sci. 93:5225-5233.
Fourichon, C., H. Seegers, and X. Malher. 2000. Effects of disease on reproduction in dairy cows: A meta-analysis. Theriogenology $53: 1729-1759$

Gier, H. T., and G. B. Marion. 1968. Uterus of the cow after parturition: Involutional changes. Am. J. Vet. Res. 29:83-96.

Gonzalez, H. E., W. A. Crowell, A. B. Caudle, and F. N. Thompson. 1985. Morphometric studies of the bovine uterus: Microscopic lesions and retrospective reproductive history. Am. J. Vet. Res. 46:2588-2595.

Gröhn, Y. T., and P. J. Rajala-Schultz. 2000. Epidemiology of reproductive performance in dairy cows. Anim. Reprod. Sci. 6061:605-614.

Kasimanickam, R., T. F. Duffield, R. A. Foster, C. J. Gartley, E. Leslie, J. S. Walton, and W. H. Johnson. 2004. Endometrial cytology and ultrasonography for detection of subclinical endometritis in postpartum dairy cows. Theriogenology 62:9-23.

Kennedy, P. C., and R. B. Miller. 1993. The female genital system. Pages 378-387 in Pathology of Domestic Animals. 4th ed. K. V. F. Jubb, P. C. Kennedy, and N. Palmer, ed. Academic Press, San Diego, CA.

Kinsel, M. L. 1996. Dairy cow postpartum disease: Definition and dilemma. Pages 3-7 in Proc. 29th Annual Convention of American Association of Bovine Practitioners (AABP), San Diego, CA. AABP, Auburn, AL.

LeBlanc, S. J. 2007. Economics of improving reproductive performance in dairy herds. WCDS Adv. Dairy Technol. 19:201-214.

LeBlanc, S. J., T. F. Duffield, K. E. Leslie, K. G. Bateman, G. P. Keefe, J. S. Walton, and W. H. Johnson. 2002. Defining and diagnosing postpartum clinical endometritis and its impact on reproductive performance in dairy cows. J. Dairy Sci. 85:2223-2236.

Mateus, L., L. L. Costa, F. Bernardo, and J. R. Silva. 2002. Influence of puerperal uterine infection on uterine involution and postpartum ovarian activity in dairy cows. Reprod. Domest. Anim. $37: 31-35$.

Miller, H. V., P. B. Kimsey, J. W. Kendrick, B. Darien, L. Doering, and C. Franti. 1980. Endometritis of dairy cattle: Diagnosis, treatment and fertility. Bovine Pract. 5:13-23.

Okano, A., and T. Tomizuka. 1987. Ultrasonic observations of postpartum uterine involution in the cow. Theriogenology 27:369-376.

Oral, H., M. Sozman, G. Serin, and S. Kaya. 2009. Comparison of the cytobrush technique, vaginoscopy, and transrectal ultrasonography methods for the diagnosis of postpartum endometritis in cows. J. Anim. Vet. Adv. 8:1252-1255.

Rodriguez, I. G., H. E. Gonzales, and M. I. M. Gallego. 1991. Correlation de la morfologia endometrial con aislamentos bacteriológicos em vacas infertiles de la sabana de Bogota. Revista ICA: Publicación Científica del Instituto Colombiano Agropecuari 26:275286

Sheldon, I. M., J. Cronin, L. Goetze, G. Donofrio, and H. Joachin. 2009. Defining postpartum uterine disease and the mechanisms of infection and immunity in the female reproductive tract in cattle. Biol. Reprod. 81:1025-1032.

Sheldon, I. M., G. S. Lewis, S. LeBlanc, and R. O. Gilbert. 2006. Defining postpartum disease. Theriogenology 65:1516-1530.

Slama, H., D. Vaillancourt, and A. K. Goff. 1991. Pathophysiology of the puerperal period: Relationship between prostaglandin $\mathrm{E}_{2}\left(\mathrm{PGE}_{2}\right)$ and uterine involution in the cow. Theriogenology 36:1071-1090.

Smith, R. D. 1991. Veterinary Clinical Epidemiology: A Problem-Oriented Approach. Butterworth-Heinemann, Boston, MA.

Williams, E. J., D. P. Fisher, G. C. W. England, H. Dobson, D. U. Pfeiffer, and I. M. Sheldon. 2005. Clinical evaluation of the postpartum vaginal mucus reflects on bacterial infection and the inflammatory response to endometritis in cattle. Theriogenology $63: 102-117$. 